JGG 2021;69:26-31

doi: 10.36150/2499-6564-462

\title{
Can we make treatment decisions by applying FRAX without BMD in Egypt?
}

\author{
Heba G. Saber ${ }^{1}$, Menna A.E.G. Aly ${ }^{1}$, Mohamed Amer² \\ ${ }^{1}$ Lecturer of Geriatrics and Gerontology, Ain Shams University, Cairo, Egypt; ${ }^{2}$ Senior Registrar of \\ Radiodiagnosis in Saudi German hospital, Cairo, Egypt
}

Background \& aims. FRAX is used to calculate the 10-year absolute risk for hip or "any major" fracture. It can be applied with/without DXA scores, in countries like Egypt where there is no calculator available, a neighboring country calculator is used. Our aim was to determine whether FRAX without DXA scores was reliable for calculating fracture risk, and which neighboring population was closest to ours.

Methods. A hospital based convenient sample study was conducted on patients referred to the outpatient radiology department for DXA over 12 months from Nov 2018 - Dec 2019. 395 patients, aging from 40-90 years, were included. Fracture risk probability was calculated using 9 calculators (Abu Dhabi, Iran, Jordan, Kuwait, Lebanon, Morocco, Palestine, Syria, Tunisia). This was done with and without BMD femoral neck obtained from DXA scan.

Results. There were 71 men and 324 women. There was a considerable agreement between the calculated risk and treatment decisions using FRAX tool with or without inclusion of BMD. Regarding sensitivity and specificity for which country calculator to base treatment decisions on; the sensitivity was relatively low with the highest sensitivity $(17 \%)$ using Kuwait, Lebanon and Syria and the lowest using Tunisia (0\%). The specificity was much higher with the highest specificity (100\%) using Jordan, Kuwait, Morocco and Palestine and the lowest specificity using Lebanon (98.6\%).

Conclusions. We can use FRAX without BMD scores for treatment decisions, but there is a need for population studies about hip fractures in Egypt to formulate our own FRAX.

Key words: FRAX, BMD, Egypt, hip fracture

How to cite this article: Saber HG, Aly MAEG, Amer M. Can we make treatment decisions by applying FRAX without BMD in Egypt? Journal of Gerontology and Geriatrics 2021;69:26-31. https://doi. org/10.36150/2499-6564-462

C Copyright by Società Italiana di Gerontologia e Geriatria (SIGG)

(c) (i) $(9)$

This is an open access article distributed in accordance with the CC-BY-NC-ND (Creative Commons Attribution-NonCommercial-NoDerivatives 4.0 International) license. The article can be used by giving appropriate credit and mentioning the license, but only for non-commercial purposes and only in the original version. For further information: https://creativecommons.org/licenses/by-nc-nd/4.0/deed.en

\section{INTRODUCTION}

Osteoporosis is defined as diminished bone strength which increases an individual's fracture risk, especially with low impact trauma ${ }^{1}$. The complications of fractures in this vulnerable group include hospitalization, institutionalization, lesser quality of life, disability and death ${ }^{2}$. Unfortunately, despite its negative health consequences, it is still a major public health problem ${ }^{3}$. Aging of the population in the Middle East and Africa means that the financial, medical and social burden will rise substantially ${ }^{4}$. Indeed, mortality rates post-hip fracture may be higher in this region than reported rates in the West, where rates vary between 25-30\%. In the Middle East and Africa region they are 2-3 times greater ${ }^{5}$. Hence, the importance of diagnosis before the occurrence of a fragility fracture is indisputable ${ }^{3}$. 
The $\mathrm{WHO}$ defines osteoporosis by measuring bone mineral density (BMD) using dual-energy $x$-ray absorptiometry (DXA). But this definition fails to identify those at risk of sustaining fragility fractures despite having BMDs above the diagnostic threshold. In fact, a greater total number of fractures occurs in these individuals ${ }^{6}$. The fracture risk assessment (FRAX) is an assessment tool developed by the World Health Organization $(\mathrm{WHO})^{7}$. It is used to calculate the patient's 10-year absolute risk for hip or "any major" fracture (including fractures of the hip, wrist, humerus, or spine). This is calculated from age, body mass index (BMI), and risk factors including prior fragility fracture, parenteral history of hip fracture, current tobacco smoking, longterm oral glucocorticoid use, rheumatoid arthritis, other causes of secondary osteoporosis and excessive alcohol consumption ${ }^{8}$.

The FRAX risk calculator is the most widely used, and it can be applied with or without including DXA scores ${ }^{7}$. The availability of DXA scans varies worldwide ${ }^{6}$, and in Egypt it is not accessible to all those at risk. According to the IOF's regional report in 2011, in Morocco, Syria, Egypt and Bahrain, DXA scanners are found mostly in big cities and private clinics ${ }^{4}$. In addition, when calculating fracture risk, we use calculators provided for neighboring Middle Eastern or North African countries (usually Jordan or Tunisia).

The aim of this work was to determine whether FRAX without DXA scores was reliable for calculating fracture risk and determining which neighboring population was closest to ours.

\section{PATIENTS AND METHODS}

A hospital based convenient sample study was conducted on patients referred to the outpatient radiology department for densitometry measurement for a period of 12 months from November 2018 to December 2019. A total number of 395 patients in the age group 40 to 90 years, of both sexes were included for the study. We excluded patients whose body weight was greater than $125 \mathrm{~kg}$ as the DXA machine couldn't accommodate them.

Height and weight were recorded for all patients. Informed consent was taken from all participants.

Patients were asked about risk factors to be entered in the FRAX tool. These risk factors include history of prior fracture, family history of parental fracture, current smoking, long term glucocorticoids use, rheumatoid arthritis, secondary osteoporosis and alcohol consumption. Hip DXA was obtained using the GE lunar Prodigy, DPX DXA system analysis version 13.6 (manufactured by GE healthcare). As per guideline of WHO, subjects were categorized based on SD into normal BMD (-1 and above) low BMD (osteopenia, between-1 and $<2.5)$ and osteoporosis (-2.5 and below).

Fracture risk probability was calculated by entering patients' information on the FRAX calculator available online (http://www.sheffield.ac.uk/FRAX/tool) for Middle East and Africa region (Abu Dhabi, Iran, Jordan, Kuwait, Lebanon, Morocco, Palestine, Syria, Tunisia). BMD femoral neck obtained from DXA scan was entered in the FRAX tool to compute FRAX with BMD fracture probability in terms of risk of major osteoporotic fracture (hip, spine, wrist and humerus).

Thus, we obtained FRAX with BMD and FRAX without BMD values for major osteoporotic fracture for all participants, and we compared agreeability of these results regarding treatment decision. We also compared sensitivity and specificity of using FRAX without BMD with the different regions if used for Egyptian patients.

SPSS (version 20, IBM SPSS statistics for windows) was used for analysis of and all data. Descriptive statistics were used to report mean, standard deviation, standard error of deviation, percentage and range. Statistical significance was set at $p<0.01$. After running the normality test on data, Pearson correlation was applied. Correlation between risk probabilities obtained for Major Osteoporotic fracture by the FRAX without BMD and FRAX with BMD was compared.

\section{RESULTS}

A total number of 395 patients with an average age of $58.74 \pm 10.82$ (range 40.2 to 87.1 years) were included in the study. There were 71 men and 324 women. The mean height was $161.37 \mathrm{~cm} \pm 8.93$, the mean weight was $83.37 \mathrm{~kg} \pm 17.14$ and the mean BMD T score at the femoral neck was $-0.97 \pm 1.22$.

According to the femoral neck BMD T score 47 (11.9\%) patients had osteoporosis and needed pharmacologic treatment according to the Pan Arab Osteoporosis Society Guidelines for Osteoporosis Management ${ }^{9}$, whilst 348 patients $(88.1 \%)$ didn't have osteoporosis and didn't need pharmacologic therapy.

The prevalence of the different risk factors calculated in FRAX risk assessment score is shown in Figure 1. The most frequent risk factor was female gender, followed by the presence of secondary Osteoporosis, parental history of hip fracture, previous fragility fractures, having Rheumatoid arthritis, being an active smoker, and having received glucocorticoids.

Table I shows the mean major osteoporotic fracture probabilities with or without inclusion of BMD in FRAX tool respectively, by calculating the scores using the 9 different ethnicities available in the Middle East and Africa region. 


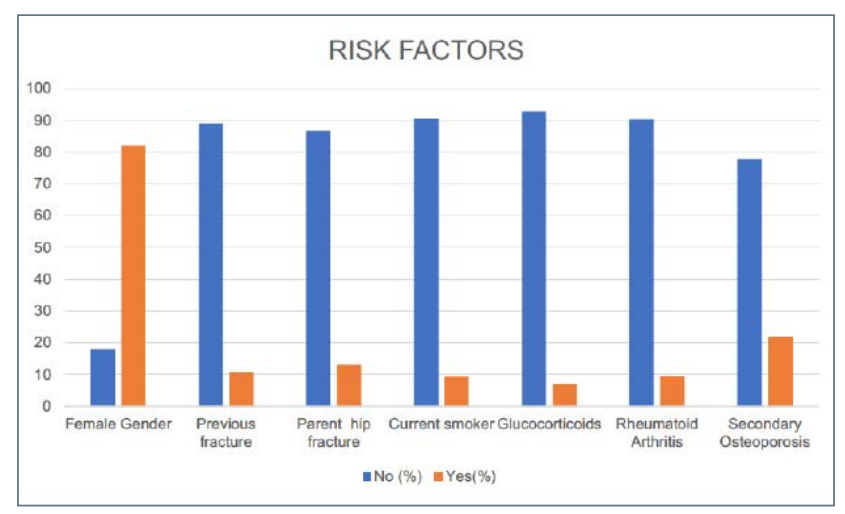

Figure 1. The prevalence of the different risk factors calculated in FRAX risk assessment score.

Table II shows the proportion of patients with osteoporosis needing pharmacologic treatment using the major osteoporotic fracture probabilities with or without inclusion of BMD in FRAX tool respectively (according to the Pan Arab Osteoporosis Society
Guidelines for Osteoporosis Management) and by calculating the scores using the 9 different ethnicities available in the Middle East and Africa region. Treatment decision was not significantly affected by using FRAX without BMD.

We used Cohen's kappa coefficient to determine agreeability between treatment decisions used with FRAX without BMD using the 9 calculators. There was only slight agreeability with Abu Dhabi, Jordan, and Palestine, a moderate agreeability with Kuwait and Iran, and substantial agreeability with Lebanon and Syria (see Table III).

We compared the treatment decisions based on the FRAX tool without BMD and the decision based on the BMD T score alone using different ethnicities to ascertain which ethnicity was most sensitive and specific, so it can be used in the Egyptian population until sufficient data is available to have the Egyptian ethnicity in the FRAX tool calculator (as shown in Table IV).

Unfortunately, the sensitivity was relatively low, with the highest sensitivity (17\%) using Kuwait, Lebanon and Syria and the lowest using Tunisia (0\%). The specificity

Table I. The mean major osteoporotic fracture probabilities with or without inclusion of BMD in FRAX tool calculated with the 9 different ethnicities available in the Middle East and Africa region.

\begin{tabular}{|l|c|c|c|c|c|c|}
\hline \multirow{2}{*}{} & \multicolumn{3}{|c|}{ With BMD } & \multicolumn{3}{c|}{ Without BMD } \\
\cline { 2 - 7 } & Mean \pm SD & Median (IQR) & Range & Mean \pm SD & Median (IQR) & Range \\
\hline Abu Dhabi & $4.32 \pm 6.09$ & $2.8(1.6-4.7)$ & $0.4-75$ & $3.74 \pm 3.71$ & $2.6(1.5-4.5)$ & $0.4-23$ \\
\hline Iran & $5.46 \pm 6.5$ & $3.6(2.3-6)$ & $1.1-72$ & $4.81 \pm 4.37$ & $3.3(2.1-5.9)$ & $0.9-24$ \\
\hline Jordan & $4.85 \pm 6.23$ & $3.3(2-5.3)$ & $0.5-75$ & $4.28 \pm 4.08$ & $3(1.9-5.4)$ & $0.4-29$ \\
\hline Kuwait & $5.05 \pm 6.16$ & $3.3(2.2-5.4)$ & $1.1-71$ & $4.45 \pm 4.21$ & $2.95(2.1-5.3)$ & $0.5-33$ \\
\hline Lebanon & $4.2 \pm 6.46$ & $2.1(1.1-4.6)$ & $0.4-75$ & $4.02 \pm 5.88$ & $1.8(1-4.1)$ & $0.3-45$ \\
\hline Morocc0 & $2.79 \pm 4.15$ & $1.8(1-3)$ & $0.4-54$ & $2.42 \pm 2.39$ & $1.6(1-2.9)$ & $0.4-15$ \\
\hline Palestine & $4.72 \pm 5.93$ & $3.3(2-5.1)$ & $0.4-69$ & $4.09 \pm 3.6$ & $2.9(1.9-5.2)$ & $0.4-22$ \\
\hline Syria & $4.14 \pm 6.37$ & $2.05(1.1-4.5)$ & $0.4-74$ & $3.95 \pm 5.73$ & $1.8(1-4)$ & $0.3-44$ \\
\hline Tunisia & $1.13 \pm 3.87$ & $0.7(0.4-1)$ & $0-74$ & $0.83 \pm 0.67$ & $0.6(0.4-1)$ & $0.2-4.6$ \\
\hline
\end{tabular}

Table II. The proportion of patients with osteoporosis needing pharmacologic treatment using the major osteoporotic fracture probabilities with or without inclusion of BMD in FRAX tool respectively.

\begin{tabular}{|l|c|c|c|c|c|c|}
\hline \multirow{2}{*}{} & \multicolumn{2}{|c|}{ With BMD } & \multicolumn{2}{c|}{ Without BMD } & \multicolumn{2}{c|}{ McNemar } \\
\cline { 2 - 7 } & No need & Needs treatment & No need & Needs treatment & P-value & sig. \\
\hline Abu Dhabi & $389(98.48 \%)$ & $6(1.52 \%)$ & $392(99.24 \%)$ & $3(0.76 \%)$ & 0.453 & NS \\
\hline Iran & $385(97.47 \%)$ & $10(2.53 \%)$ & $387(97.97 \%)$ & $8(2.03 \%)$ & 0.727 & NS \\
\hline Jordan & $389(98.48 \%)$ & $6(1.52 \%)$ & $389(98.48 \%)$ & $6(1.52 \%)$ & 1 & NS \\
\hline Kuwait & $387(97.97 \%)$ & $8(2.03 \%)$ & $387(97.97 \%)$ & $8(2.03 \%)$ & 1 & NS \\
\hline Lebanon & $385(97.47 \%)$ & $10(2.53 \%)$ & $382(96.71 \%)$ & $13(3.29 \%)$ & 0.453 & NS \\
\hline Morocco & $393(99.49 \%)$ & $2(0.51 \%)$ & $395(100 \%)$ & $0(0 \%)$ & 0.5 & NS \\
\hline Palestine & $389(98.48 \%)$ & $6(1.52 \%)$ & $393(99.49 \%)$ & $2(0.51 \%)$ & 0.219 & NS \\
\hline Syria & $384(97.22 \%)$ & $11(2.78 \%)$ & $383(96.96 \%)$ & $12(3.04 \%)$ & 1 & NS \\
\hline Tunisia & $393(99.49 \%)$ & $2(0.51 \%)$ & $395(100 \%)$ & $0(0 \%)$ & 0.5 & NS \\
\hline
\end{tabular}


Table III. Degree of agreement between using FRAX without DXA and T-score alone, and the decision to treat.

\begin{tabular}{|c|c|c|c|c|c|c|c|}
\hline \multicolumn{2}{|l|}{ Calculator used } & \multicolumn{2}{|c|}{ With T-score } & \multirow[t]{2}{*}{ Total } & \multicolumn{3}{|c|}{ Agreement } \\
\hline & & No need & Needs treatment & & $\%$ & Kappa & p-value \\
\hline \multirow{2}{*}{$\begin{array}{l}\text { Abu Dhabi FRAX } \\
\text { without BMD }\end{array}$} & No need & $387(98.0 \%)$ & $5(1.2 \%)$ & $392(99.2 \%)$ & $98.2 \%$ & 0.2 & $<0.001$ \\
\hline & $\begin{array}{l}\text { Needs } \\
\text { treatment }\end{array}$ & $2(0.5 \%)$ & $1(0.3 \%)$ & $3(0.8 \%)$ & & & \\
\hline \multirow{2}{*}{$\begin{array}{l}\text { Iran FRAX without } \\
\text { BMD }\end{array}$} & No need & $382(96.7 \%)$ & $5(1.3 \%)$ & 387 (98.0\%) & $98.0 \%$ & 0.5 & $<0.001$ \\
\hline & $\begin{array}{l}\text { Needs } \\
\text { treatment }\end{array}$ & $3(0.8 \%)$ & $5(1.3 \%)$ & $8(2.0 \%)$ & & & \\
\hline \multirow{2}{*}{$\begin{array}{l}\text { Jordan FRAX } \\
\text { without BMD }\end{array}$} & No need & $384(97.2 \%)$ & $5(1.3 \%)$ & $389(98.5 \%)$ & $97.5 \%$ & 0.2 & 0.002 \\
\hline & $\begin{array}{l}\text { Needs } \\
\text { treatment }\end{array}$ & $5(1.3 \%)$ & $1(0.3 \%)$ & $6(1.5 \%)$ & & & \\
\hline \multirow{2}{*}{$\begin{array}{l}\text { Kuwait FRAX } \\
\text { without BMD }\end{array}$} & No need & $383(97.0 \%)$ & $4(1.0 \%)$ & $387(98.0 \%)$ & $98.0 \%$ & 0.5 & $<0.001$ \\
\hline & $\begin{array}{l}\text { Needs } \\
\text { treatment }\end{array}$ & $4(1.0 \%)$ & $4(1.0 \%)$ & $8(2.0 \%)$ & & & \\
\hline \multirow{2}{*}{$\begin{array}{l}\text { Lebanon FRAX } \\
\text { without BMD }\end{array}$} & No need & $380(96.2 \%)$ & $2(0.5 \%)$ & $382(96.7 \%)$ & $98.2 \%$ & 0.687 & $<0.001$ \\
\hline & $\begin{array}{l}\text { Needs } \\
\text { treatment }\end{array}$ & $5(1.3 \%)$ & $8(2.0 \%)$ & $13(3.3 \%)$ & & & \\
\hline $\begin{array}{l}\text { Morocco FRAX } \\
\text { without BMD }\end{array}$ & No need & $393(99.5 \%)$ & $2(0.5 \%)$ & 395 (100\%) & & & \\
\hline \multirow{2}{*}{$\begin{array}{l}\text { Palestine FRAX } \\
\text { without BMD }\end{array}$} & No need & $388(98.2 \%)$ & $5(1.3 \%)$ & $393(99.5 \%)$ & $98.5 \%$ & 0.2 & $<0.001$ \\
\hline & $\begin{array}{l}\text { Needs } \\
\text { treatment }\end{array}$ & $1(0.25 \%)$ & $1(0.3 \%)$ & $2(0.5 \%)$ & & & \\
\hline \multirow{2}{*}{$\begin{array}{l}\text { Syria FRAX without } \\
\text { BMD }\end{array}$} & No need & $380(96.2 \%)$ & $3(0.8 \%)$ & $383(97.0 \%)$ & $98.2 \%$ & 0.7 & $<0.001$ \\
\hline & $\begin{array}{c}\text { Needs } \\
\text { treatment }\end{array}$ & $4(1.0 \%)$ & $8(2.0 \%)$ & $12(3.0 \%)$ & & & \\
\hline $\begin{array}{l}\text { Tunisia FRAX } \\
\text { without BMD }\end{array}$ & No need & 393 (99.5\%) & $2(0.5 \%)$ & $395(100 \%)$ & & & \\
\hline
\end{tabular}

Table IV. Sensitivity and specificity of using FRAX without BMD using different calculators.

\begin{tabular}{|l|c|c|c|c|c|}
\hline & Sensitivity & Specificity & PPV & NPV & Accuracy \\
\hline Abu Dhabi without & $4.3 \%$ & $99.7 \%$ & $66.7 \%$ & $88.5 \%$ & $88.4 \%$ \\
\hline Iran without & $8.5 \%$ & $98.9 \%$ & $50.0 \%$ & $88.9 \%$ & $88.1 \%$ \\
\hline Jordan without & $12.8 \%$ & $100.0 \%$ & $100.0 \%$ & $89.5 \%$ & $89.6 \%$ \\
\hline Kuwait without & $17.0 \%$ & $100.0 \%$ & $100.0 \%$ & $89.9 \%$ & $90.1 \%$ \\
\hline Lebanon without & $17.0 \%$ & $98.6 \%$ & $61.5 \%$ & $89.8 \%$ & $88.9 \%$ \\
\hline Morocco without & $0.0 \%$ & $100.0 \%$ & & $88.1 \%$ & $88.1 \%$ \\
\hline Palestine without & $4.3 \%$ & $100.0 \%$ & $100.0 \%$ & $88.5 \%$ & $88.6 \%$ \\
\hline Syria without & $17.0 \%$ & $98.9 \%$ & $66.7 \%$ & $89.8 \%$ & $89.1 \%$ \\
\hline Tunisia without & $0.0 \%$ & $100.0 \%$ & & $88.1 \%$ & $88.1 \%$ \\
\hline
\end{tabular}

was much higher with the highest specificity (100\%) using Jordan, Kuwait, Morocco and Palestine and the lowest specificity using Lebanon (98.6\%).

Table $\mathrm{V}$ aims to identify the correlation between Frax with and without BMD with T scores. All the ethnicities, whether with or without BMD, were significantly inversely correlated with femoral neck t score with a range of $r$ from -0.38 (Tunisia with BMD) to -0.642 (Iran with $\mathrm{BMD}$ ). The correlation was always stronger using FRAX with BMD than without BMD except in Tunisia where with was slightly weaker (-0.38) than without, which had a moderate correlation with $r$ value -0.461 .

\section{DISCUSSION}

Currently there is no FRAX calculator for the Egyptian population due to a lack of a local hip fracture database. The FRAX website provides it for 9 different countries in the Middle East and Africa region (Abu Dhabi, Iran, 
Table V. Correlation between FRAX with and without BMD with T-scores of the studied group.

\begin{tabular}{|l|c|c|c|}
\hline \multirow{2}{*}{} & \multicolumn{3}{|c|}{ Femoral neck T-score } \\
\cline { 2 - 4 } & $\mathbf{r}$ & P-value & sig \\
\hline Abu dhabi & -0.613 & $<0.001$ & $\mathrm{~S}$ \\
\hline Abu dhabi without BMD & -0.471 & $<0.001$ & $\mathrm{~S}$ \\
\hline Iran & -0.642 & $<0.001$ & $\mathrm{~S}$ \\
\hline Iran without BMD & -0.467 & $<0.001$ & $\mathrm{~S}$ \\
\hline Jordan & -0.629 & $<0.001$ & $\mathrm{~S}$ \\
\hline Jordan without BMD & -0.47 & $<0.001$ & $\mathrm{~S}$ \\
\hline Kuwait & -0.632 & $<0.001$ & $\mathrm{~S}$ \\
\hline Kuwait without BMD & -0.451 & $<0.001$ & $\mathrm{~S}$ \\
\hline Lebanon & -0.598 & $<0.001$ & $\mathrm{~S}$ \\
\hline Lebanon without BMD & -0.408 & $<0.001$ & $\mathrm{~S}$ \\
\hline Morocc0 & -0.596 & $<0.001$ & $\mathrm{~S}$ \\
\hline Morocco without BMD & -0.47 & $<0.001$ & $\mathrm{~S}$ \\
\hline Palestine & -0.626 & $<0.001$ & $\mathrm{~S}$ \\
\hline Palestine without BMD & -0.479 & $<0.001$ & $\mathrm{~S}$ \\
\hline Syria & -0.598 & $<0.001$ & $\mathrm{~S}$ \\
\hline Syria without BMD & -0.408 & $<0.001$ & $\mathrm{~S}$ \\
\hline Tunisia & -0.38 & $<0.001$ & $\mathrm{~S}$ \\
\hline Tunisia without BMD & -0.461 & $<0.001$ & $\mathrm{~S}$ \\
\hline
\end{tabular}

Jordan, Kuwait, Lebanon, Morocco, Palestine, Syria, and Tunisia). So, when a physician in Egypt uses the calculator they will choose one of the above (Jordan and Tunisia are most frequently used). In situations where there is no FRAX model for a country a representative country with similar fracture incidence can be chosen ${ }^{10}$.

Another problem is that DXA scans are not readily available to all those who need screening. Our aim was to address this issue by comparing FRAX with DXA scores to FRAX without; to find out which ethnicity was most sensitive and specific in detecting fracture risk in Egyptian patients, and relate these to the need to treat.

In our study we found that $11.9 \%$ of those referred for DXA scanning were actually Osteoporotic. This was slightly higher than the prevalence of Osteoporosis in Orthopedic outpatient clinics in Southern India, which was $9 \%$ in those older than 55 years respectively ${ }^{11}$.

The FRAX calculator takes into account age, gender, body mass index (BMI), and the following risk factors; prior fragility fracture, parenteral history of hip fracture, current tobacco smoking, long-term oral glucocorticoid use, rheumatoid arthritis, other causes of secondary osteoporosis and excessive alcohol consumption.

In the studied sample the most frequent risk factor was female gender, followed by the presence of secondary Osteoporosis, parental history of hip fracture, previous fragility fractures, having Rheumatoid arthritis, being an active smoker, and having received glucocorticoids.
In our study we compared FRAX score with BMD to FRAX score calculated without using the 9 different calculators. We found that there was no significant difference between the scores. This agreed with the findings of several studies ${ }^{12,13}$. On the other hand, llias et al. ${ }^{14}$ showed that in Greek women using FRAX without BMD did not accurately reflect fracture risk.

We also determined the agreement with treatment decision between using FRAX score with and without BMD using the 9 selected calculators (as determined by the Pan Arab Osteoporosis Society Guidelines for Osteoporosis Management) ${ }^{9}$. The strength of agreeability varied between the different countries, with substantial agreeability with Lebanon and Syria, moderate agreeability with others (Kuwait and Iran), and slight agreeability with Abu Dhabi, Jordan, and Palestine.

A cross sectional study carried out on Pakistani women concluded that using FRAX to calculate risk without using DXA scores could efficiently predict treatment need in those at risk. According to the authors DXA scans were also not easily accessible their country ${ }^{15}$. Another study carried on a historical cohort by Leslie et al., ${ }^{16}$ also supported this statement by asserting that FRAX without BMD is sufficient for treatment decisions. Kim et al., ${ }^{17}$ echoed these findings in their work and observed that since using FRAX without BMD was accurate, this would be useful in regions were DXA scans could not be done.

On the other hand, there are studies which disagree. One such study observed that when calculating FRAX without BMD there was an over estimation of fracture risk ${ }^{18}$. A Korean study found that in males there was an underestimation of fracture risk when BMD was not used, whilst females there was no difference between using BMD or not ${ }^{19}$. But in both studies, it must be stated that they included special groups of patients; females with early breast cancer in the former, and patients with ankylosing spondylitis in the later.

Another conclusion reached by Bow et al., is that ultimately BMD scores are important in refining the estimate of fracture risk ${ }^{20}$.

When we compared treatment decisions based on FRAX without BMD (calculated using the 9 country calculators), to treatment decisions based on $T$ scores alone to determine which calculator was most sensitive and specific the following was observed; the sensitivity was relatively low with the highest sensitivity (17\%) using Kuwait, Lebanon and Syria and the lowest using Tunisia (0\%). The specificity was much higher with the highest specificity (100\%) using Jordan, Kuwait, Morocco and Palestine and the lowest specificity using Lebanon (98.6\%).

According to Kanis et al. ${ }^{21}$, who performed a systematic review of hip fracture incidence and fracture probability 
worldwide, there is a marked variation around the world. Accordingly, using calculators from different countries may not accurately reflect true fracture risk. This can explain why there was such low sensitivity, and highlight the need for creating an Egyptian Hip fracture registry to enable the creation of an Egyptian calculator.

A significant inverse correlation was observed between FRAX with/out BMD and femur neck T score.

\section{CONCLUSIONS}

In conclusion, our findings demonstrate that, for the time-being, we can use FRAX without BMD scores to decide who we can offer treatment to. This is very important in our country because currently DXA scans cannot be offered to all those who need it. But because the sensitivity of the different regional calculators often used for the Egyptain population was relatively low, to reiterate what was said above, there is a pressing need to start collecting information about hip fractures at the population level in Egypt.

\section{Acknowledgements}

The authors would like to thank the Radiology department in Saudi German Hospital Cairo, Egypt, who helped provide valuable data for this work.

\section{References}

$1 \mathrm{NIH}$ Consensus Development Panel on Osteoporosis Prevention, Diagnosis, and Therapy. NIH consensus development panel on osteoporosis prevention, diagnosis and treatment. Osteoporosis prevention, diagnosis, and therapy. JAMA 2001;285:785-95.

2 Beaupre LA, Jones CA, Saunders LD, et al. Best practices for elderly hip fracture patients. A systematic overview of the evidence. J Gen Intern Med 2005;20:1019-25. https:// doi.org/10.1111/j.1525-1497.2005.0219.x

3 Cosman F, de Beur SJ, LeBoff MS, et al. Clinician's guide to prevention and treatment of osteoporosis. Osteoporosis Int 2014;25:2359-81. https://doi.org/10.1007/s00198014-2794-2

4 The middle east \& Africa Regional Audit. Epidemiology, costs and burden of osteoporosis in 2011 (https://www. iofbonehealth.org/sites/default/files/PDFs/Audit\%20Middle\%20East_Africa/ ME_audit-executive_summary.pdf).

5 Baddoura R, Hoteit M, Fuleihan GE. Osteoporotic fractures, DXA, and fracture risk assessment: meeting future challenges in the eastern Mediterranean region. J Clin Densitometry 2011;14:384-94. https://doi.org/10.1016/j. jocd.2011.03.009

6 Curtis EM, Moon RJ, Harvey NC, et al. Reprint of: the impact of fragility fracture and approaches to osteoporosis risk assessment worldwide. Int J Orthop Traum Nurs 2017;26:7-17.
7 Kanis JA, Johnell O, Odén A, et al. FRAX'TM and the assessment of fracture probability in men and women from the UK. Osteoporosis Int 2008;19:385-97.

8 Tuzun S, Eskiyurt N, Akarırmak U, et al. Incidence of hip fracture and prevalence of osteoporosis in Turkey: the FRACTURK study. Osteoporos Int 2012;23:949-55. https://doi.org/10.1007/s00198-011-1655-5

9 Jassim NA, Adib G, Younis AA, et al. Pan Arab Osteoporosis Society Guidelines for Osteoporosis Management. Mediterr J Rheumatol 2017;28:27-42. https://doi. org/10.1001/archinte.164.10.1108

10 Siris ES, Chen YT, Abbott TA, et al. Bone mineral density thresholds for pharmacological intervention to prevent fractures. Arch Int Med 2004;164:1108-12.

11 Chitten JJ, James B. Prevalence of osteopenia and osteoporosis in orthopaedic outpatients in Southern India. J Clin Diagn Res 2018;12.

12 Sarikaya NO, Yavasi SK, Tan G, et al. Agreement between FRAX scores calculated with and without bone mineral density in women with osteopenia in Turkey. Clin Rheumatol 2014;33:1785-9. https://doi.org/10.1007/s10067014-2491-8

13 Gadam RK, Schlauch K, Izuora KE. Frax prediction without BMD for assessment of osteoporotic fracture risk. Endocr Pract 2013;19:780-9. https://doi.org/10.4158/EP12416. OR

14 Ilias I, Spanoudi F, Koukkou E, et al. Use of the FRAX calculator with and without bone mineral density in Greek women. Hormones 2012;11:222-3.

15 Sadiq M, Hassan N, Sattar S, et al. The WHO FRAX calculator with and without BMD as an indicator of low BMD in Pakistani Women. J Adv Med Medical Res 2016:1-7. https://doi.org/10.9734/BJMMR/2016/30003

16 Leslie WD, Morin S, Lix LM, et al. Fracture risk assessment without bone density measurement in routine clinical practice. Osteoporos Int 2012;23:75-85.

17 Kim JW, Koh JM, Park JH, et al. Validation of FRAX without BMD: an age-related analysis of the Fifth Korean National Health and Nutrition Examination Survey (KNHANES V-1, 2010). Bone 2015;75:27-31. https://doi.org/10.1016/j. bone.2015.02.013

18 Prawiradilaga RS, Gunmalm V, Lund-Jacobsen T, et al. FRAX calculated without BMD resulting in a higher fracture risk than that calculated with BMD in women with early breast cancer. J Osteoporosis 2018;2018.

19 Kwon SR, Choi ST, Suh CH, et al. The disparities between fracture risk assessment (FRAX) with BMD and without BMD in Korean patients with ankylosing spondylitis-multicenter trial, 2017, pp. 1355-6.

20 Bow CH, Tsang SW, Loong CH, et al. Bone mineral density enhances use of clinical risk factors in predicting ten-year risk of osteoporotic fractures in Chinese men: the Hong Kong Osteoporosis Study. Osteoporosis Int 2011;22:2799807. https://doi.org/10.1007/s00198-010-1490-0

21 Kanis JA, Oden A, McCloskey EV, et al. A systematic review of hip fracture incidence and probability of fracture worldwide. Osteoporosis Int 2012;23:2239-56. 